\title{
MARCELINO PAN Y VINO UNA PELÍCULA FUNDACIONAL DEL ENMASCARAMIENTO DE LA ORFANDAD POLÍTICA
}

\author{
MARCELINO PAN Y VINO, A FOUNDATIONAL FILM \\ ABOUT MASKING POLITICAL ORPHANHOOD
}

\section{Rita De Grandis}

The University of British Columbia

Vancouver, Canadá

\begin{abstract}
Resumo
Marcelino pan y vino (1954), do diretor húngaro Ladislao Vajda, com a atuação estelar de Pablito Calvo é um filme baseado em um conto popular religioso, cuja versão escrita é de autoria de José María Sánchez Silva (1952), que participou da escrita do roteiro. O estudo se concentra na análise fílmica; na inversão dos papéis de gênero pela qual se feminiza os frades no seu rol maternal; na elipse temporal na qual se situa a historia (1808-14) e na origem misteriosa de Marcelino, dentre os elementos mais destacados. Da mesma forma, busca-se demonstrar mediante os preconceitos religiosos e a repressão política, como o filme mascara o trauma da Guerra civil espanhola e as centenas de crianças órfấs que resultaram do conflito.

Finalmente, conclui-se vinculando o filme com o monumento do Valle de los caídos como outro gesto simbólico religioso de reconciliação sobre a guerra fratricida.
\end{abstract} Palavras-chave: religião; orfandade; origem; repressão; infância; elipse; folclore.

\section{Resumen}

Marcelino pan y vino (1954) del director húngaro Ladislao Vajda, y con la actuación estelar de Pablito Calvo es un film basado en un cuento popular religioso cuya versión escrita es de la autoría de José María Sánchez Silva (1952) quien participó de la escritura del guión.

Este estudio se concentrará en el análisis fílmico; en la inversión de roles genéricos por la cual se feminiza a los frailes en su rol maternal, en la elipsis temporal en la que se sitúa la historia (1808-14), en el origen misterioso de Marcelino, entre los elementos más salientes. Asimismo se demostrará mediante los prejuicios religiosos y la represión política como el film enmascara el trauma de la Guerra civil española y los cientos de niños huérfanos como resultado del conflicto.

\section{Abstract}

Marcelino pan y vino (1954) directed by Hungarian Ladislao Vajda, with the stellar participation of Pablito Calvo in the role of Marcelino is based on a popular religious story whose written version is authored by José María Sánchez Silva (1952).

This study will focus on film analysis including: gender role inversion by which friars are feminized in their maternal role; temporal ellipsis situating the story in 1808-14; Marcelino and his mystery of origin, among some of the most salient aspects of the film. Moreover, the study argues that the religious and political prejudices are masked in order to render a mythological origin of an orphan child as a way to deal with the trauma of the 
Finalmente, se concluirá vinculando el film con el monumento del Valle de los Caídos como otro gesto simbólico religioso de reconciliación sobre la Guerra fratricida.

Palabras clave: religión; orfandad; origen; represión; niñez; elipsis; folklore.
Spanish Civil War in which hundreds of children were left orphans.

Finally, it will conclude relating the film to the monument of the "Valle de los Caídos" as another religious symbolic act promoting social reconciliation about a fratricidal conflict.

Keywords: religion; orphanhood; origen; repression; childhood; ellipsis; folklore.

A principios de los años cincuenta el régimen franquista comienza a salir del aislamiento en el plano cinematográfico gracias a la llegada de grandes profesionales de reconocido prestigio y experiencia como el director judío de origen húngaro Ladislao Vajda (1906-1965), ${ }^{1}$ considerado el húngaro más español de la historia de la cultura en los años cincuenta (CAMPORESI, 2007). ${ }^{2}$ El cine de tema religioso vive un renacimiento bajo los auspicios del nacional-catolicismo vigente entonces, según el Concordato con la Santa Sede que Franco había firmado en 1941, por el cual el propio Franco tenía la potestad de nombrar a los prelados españoles y a cambio el Estado asumía la sustentación económica de la Iglesia, es decir, el salario de los clérigos, la reconstrucción de los templos, el mantenimiento de los seminarios y la financiación de las misiones (RUBIO, 2014). ${ }^{3}$ Así, aparecieron filmes religiosos de gran repercusión internacional, como Marcelino pan y vino de Vajda (1954), la milagrosa historia de un niño (Pablito Calvo), abandonado en el portal de una iglesia y recogido por monjes franciscanos que se transforman en padres y madres de este niño. La eventual devoción del niño por una gran estatua de

\footnotetext{
${ }^{1}$ Director, húngaro homónimo de su padre, obligado a exiliarse en 1919 primero en Viena y luego en Berlín; dramaturgo y guionista. Murió repentinamente el 26 de marzo de 1965 en Barcelona cuando rodaba La dama de Beirut con Sarita Montiel. El montaje fue su primer oficio antes de la dirección. Al verse obligado a huir del nacional-socialismo hitleriano; huyó de la segunda guerra mundial buscando amparo en la España de Franco donde las circunstancias le permitían seguir trabajando en lo suyo en 1942. En los ańos cincuenta dado el sistema oficial, de apoyo económico al "cine declarado de interés nacional" se dedicó su producción dentro del género castizo (Francisquita y más tarde Las aventuras del Barbero de Sevilla, Carne de Horca (1953) y Tarde de toros (1955)) el tema religioso.

${ }^{2}$ Dos fechas son indicativas de este fenómeno de españolización oficial; en 1952 recibió la Orden de Isabel la Católica y en 1954 se naturalizó como ciudadano español.

${ }^{3}$ El rebrote del tema de la niñez en el cine europeo de los años 50 es ajeno al babies-star-system. Después de las matanzas y los horrores de las recientes guerras, tienen algo que ver con una reflexión sobre las víctimas inocentes que las sufrieron y el cine aportó representaciones sobre las consecuencias humanitarias de los conflictos bélicos mundiales y en la miseria de tantos huérfanos desvalidos, abandonados a sí mismos como en Quelque part en Europe de Radványi y Bela Balasz, Alemania año cero de Roberto Rossellini, o El limpiabotas de Victorio de Sica, por dar algunos ejemplos. El propio Buńuel en su exilio mexicano llevó a cabo Los olvidados (1950) (GUBERN, 2001).
} 
Cristo agonizante en la cruz lo llevará finalmente a su muerte en brazos de ese Cristo. La representación de la muerte en plena infancia se celebra como un milagro para el niño y para la comunidad como una afirmación de su cohesión (HARVEY, 2004).

Volver a estudiar la película original denostada por la crítica de cine española por su directa asociación con la ideología franquista, y repuesta comercialmente en España en 1979, formó parte de la historia personal, nacional e internacional de muchos, y continúa siéndolo en otros contextos.

Marcelino pan y vino quedó en mi mente como un hito cinematográfico de mi infancia en Argentina que de pronto rememoré a partir de filmes producidos en la primera década del nuevo milenio, como Los niños de Rusia (2001) de Jaime Camino, Los niños de Morelia (2004) de Juan Pablo Villaseñor, entre otros documentales y filmes de ficción histórica como La lengua de las mariposas (1999), El viaje de Carol (2002), El laberinto del Fauno (2006), resultado de políticas sobre la memoria de la Guerra Civil y de la Dictadura de Franco corroboradas mediante la Ley de la Memoria Histórica sancionada en el año 2007 durante el gobierno de José Luis Rodríguez Zapatero (2004-2011).

Me interesa indagar cómo Marcelino Pan y Vino, a pesar su catoliquísimo contenido, de haber pasado la censura, de haber obtenido los más altos calificativos oficialistas, es susceptible de una lectura "otra" en tanto que el filme trasciende dicha ideología por la complejidad de los mecanismos formales de funcionamiento y estructuras de significación que ponen en entredicho una visión que sólo remitiría a los condicionamientos políticos de la industria cinematográfica del momento y de la ideología del nacional-catolicismo imperante entonces. Siguiendo la hipótesis de Anne-Marie Jolivet (2003), Vajda articula desde una perspectiva universalista humanista elementos de la puesta en escena y del montaje, mediante los cuales se abordan ciertos tabúes de época, plasmando en imágenes una dimensión antropológica de lo sagrado y del mito. Sostendremos que Marcelino Pan y Vino representa de modo simbólico al huérfano como niño mesiánico, víctima fundacional cuya muerte viene a saldar un pacto de reconciliación nacional.

Marcelino Pan y Vino es adaptación del cuento homónimo, publicado en 1952, de enorme éxito editorial (unas cien ediciones en tres años) del escritor católico José María Sánchez Silva (1911-2002), quien además colaboró en el guión. ${ }^{4}$ El cuento tiene su origen en la tradición oral de larga data en

\footnotetext{
${ }^{4}$ En el cuento literario Sánchez Silva remonta la tradición oral y el recuerdo de una historia que le contaba su madre cuando era niño; Sánchez Silva se lo dedica a su hija mayor que a los 19 años se hizo novicia en un convento y Jolivet sugiere que es "un regalo simbólico del padre a su hija" (31). Vajda y Sánchez Silva escribieron el guión conjuntamente y pasó la censura el 25 de agosto
} 
Europa, retomada incluso por los hermanos Grimm, que la madre del escritor le contaba: "Del pobre huérfano que cada día al pasar con su madre delante de la imagen de una Virgen, compartía su merienda con el niño Jesús, y recibió en recompensa la invitación a merendar con él en el paraíso" (JOLIVET, 2003: 34). Del cuento de la madre a su creación literaria cambia las figuras maternas por la de los monjes y la de Cristo por la del niño. ${ }^{5}$

La estructura narrativa del filme es una mise en abyme, es decir, "la historia de la historia de Marcelino" contada por un joven fraile a una nińa enferma y a sus padres. Las secuencias introductivas y conclusivas que analizaremos como prólogo y epílogo son diegéticamente contemporáneas de la época del rodaje, mientras que el flashback sobre la vida del pequeño héroe remite al tiempo de la invasión napoleónica (1808-14). Por otro lado, la muerte del niño, resultado de una prohibición/recompensa, está tratada de un modo abstracto, introduciendo un grado de complejidad simbólica que abre el campo de la interpretación a perspectivas psicoanalíticas, antropológicas y filosóficas. ${ }^{6}$

\section{Prólogo. Una alegoría de la nación}

La película comienza con una voz en off cargada de afecto y pertenencia: "Es mi pueblo y lo quiero. Sus casas y sus gentes son sencillas. Los quiero en sus alegrías y en sus dolores. Hoy están contentos con la romería." Luego la voz enunciadora comenta: "Todos suben para festejar algo quizás perdido en el recuerdo de algunos pero que sigue sonando en el corazón de muchos.” ¿De qué acontecimiento se trata? ¿Qué es eso "olvidado" o "recordado?" A nivel de la representación observamos la primera ambigüedad: la ausencia en esta romería de oficiales de la Iglesia dado que en la época en que el filme se rodó (en pleno Concordato), la Iglesia y los eclesiásticos estaban presentes y eran omnipresentes en semejantes festejos. Como sostiene Jolivet, la elección de Vajda es más antropológica: se sitúa fuera de la religión oficial poco favo-

\footnotetext{
y el 27 de agosto de 1954 cuando obtuvo el permiso de rodaje que empezó el 8 de septiembre y se acabó el 15 de diciembre del mismo año. Se estrenó en el Coliseum de Madrid el 24 de febrero de 1955. Fue un éxito rotundo; estuvo en cartelera 105 días seguidos, lo cual no era frecuente en aquella época. La película fue clasificada en la categoría Primera $A$ en la comisión reunida el 25 de febrero de 1955 y se le otorgó el crédito sindical de 2.400 .000 de pesetas. Al cabo de un mes, y dado su exitoso estreno en Madrid, fue declarada digna de la suprema calificación de Interés nacional, lo cual representaba un sustancioso suplemento que permitió cubrir casi por completo el presupuesto de la película de aproximadamente unos seis millones de pesetas) (JOLIVET, 2003: 32).

${ }^{5}$ El propio escritor fue un huérfano ya que desde pequeño se quedó sin padre y a los 11 ańos perdió a su madre por lo cual ingresó a un orfanato.

${ }^{6}$ Vajda, lector de Freud y de su compatriot Sandor Ferenczy, propone un enfoque modern susceptible a interpretaciones psicoanalíticas, como por ejemplo la relación de un niño húerfano que busca en la relación simbólica del Padre, la mediación redentora que lo salve del encierro conventual donde impera la no-alteridad sexual.
} 
rable a festejos y excesos populares (aunque también el franquismo fomentó una cierta "esencia" del pueblo español). Los cantos, la risa, las bromas ("las lomas castellanas que parecen pechos de virgen") apuntan a una dimensión vitalista, en que las personas suben la loma para celebrar un tipo de asunción de naturaleza más terrenal que celestial.

Mientras todos suben, un fraile baja al pueblo (Fernando Rey 19171994). El fraile viene a ver a una nińa moribunda, cuyo padre expresa desagrado cuando el fraile le cuenta a la nińa la historia de Marcelino que se celebra ese día. Si la muerte es próxima, la intervención del hombre de Dios con su historia sería como el sacramento de la extremaunción para ayudar a la niña a la muerte.

\section{Ambigüedades históricas}

He aquí que la dimensión alegórica se hace presente. La voz en off propone un rápido resumen de las imágenes de la independencia. Se habla de una España rural detenida en el tiempo desde la "Guerra de la independencia” contra las fuerzas napoleónicas (1808-14). "Habíamos vencido, pero sobre nuestras propias ruinas. Todos lo preferíamos aun asî". "Las cosechas volvieron a nacer, los árboles quemados y secos curaron de sus heridas, las casas derribadas se levantaron de nuevo. Todo empezó a revivir...” Esta voz patriótica de renacimiento y reconstrucción marca el límite borroso entre las dos épocas, contribuyendo a la ambigüedad temporal respecto de una realidad nacional ya que España vivía entonces prácticamente política y culturalmente en autarquía, es decir aislada. Desde el principio, cuando el joven fraile evoca la resistencia nacional a la invasión francesa se percibe un desliz hacia el doble discurso ideológico pasado/presente en que la guerra se presenta como un sacrificio compartido vinculado al simbolismo religioso de muerte y resurrección. Esta re-contextualización evoca otros recuerdos de una guerra fratricida mucho más reciente que aún perdura en las conciencias españolas, aunque, para los niños sobre todo, permaneciera en el mundo censurado de lo no dicho o hablado. En este contexto histórico del conflicto del pasado observamos un deslizamiento hacia el discurso oficial del franquismo. Es de notar que los comentarios sobre las exacciones no aluden a iglesias o conventos incendiados por los franceses, o por los malos españoles, como afirma Jolivet, sino sólo a "casas y cosechas quemadas. Acaso lo importante fuera acallar pasiones pasadas en vistas de una reconciliación ecuménica de los hermanos enemigos" (JOLIVET, 2003: 53).

Hay una segunda intervención de la voz en off que comenta la elipsis temporal con tono de oralidad, dando cuenta de que el valor del esfuerzo 
mancomunado es premiado con el primer milagro de la historia, que es el bebé abandonado que puede interpretarse como una ofrenda de vida como recompensa.

\section{El cuerpo fílmico. El enigma del origen}

De esa introducción en estructura narrativa abismada, pasamos al encuentro del niño abandonado. Pero, ¿̇de dónde sale el nińo y quiénes son sus padres? Se evoca el posible robo del nińo, o bien el abandono por una madre "avergonzada y desgraciada". Para los espectadores adultos, esos adjetivos aluden claramente a la situación de oprobio y de desamparo en la que la sociedad mantenía entonces a las madres solteras (JOLIVET, 2003: 68). Luego viene el registro de lo sagrado. Con una concha se bautiza al niño y se le da el nombre del santo del día, Marcelino. Empiezan las investigaciones en busca de la familia del pequeño. El Padre Superior dice: "Los padres de Marcelino no existen," y fray Gil declara: "estarán en el cielo," suponiendo su muerte, o su realidad no terrenal. Fray Tomás agrega: "Necesita una madre," dejando sentado que una comunidad familiar donde no existe la alteridad sexual no le conviene al niño. Este discurso remite al tabú sexual y a lo no-dicho sobre la procreación, que, según la educación de los niños en la época del rodaje de la película, no se hablaba con claridad de los misterios de los orígenes y de la procreación. En cambio, se solía aludir al tema con metáforas de animales (la cigüeña) o la mitificación del viaje de boda a París, de donde venían los niños. ${ }^{7}$ De acuerdo con Jolivet, desde el punto de vista narrativo este tema resulta ser el más enrevesado de la película, haciendo del origen del expósito un enigma o una mistificación que se vincula con los esquemas antropológicos del niño sobrenatural de origen desconocido o divino. Al fin, luego de infructuosas búsquedas de hogar para el bebé Marcelino, los frailes deciden quedárselo ellos y criarlo en el convento declarando que será un franciscano más como ellos.

Fiel a la lógica narrativa del flashback, la voz en offenunciadora comenta la elipsis y la imagen. Marcelino al cabo de 5 años "ya era un chico robusto y avispado;" las imágenes aluden a un niño universal, un chico de cinco años como todos, que cambia el nombre de los frailes según su ocupación, como fray Papilla, la figura más maternal de todas, que es el cocinero. La infancia de Marcelino era un paraíso como la de San Francisco corroborada por un cuadro visible en profundidad de campo. Se ve al niño entre las sábanas al

\footnotetext{
${ }^{7}$ Por otro lado, la mitificación del origen tiene justificación antropológica puesto que corresponde a los primeros esquemas del psiquismo infantile respect al tema del origen y de la diferencia sexual.
} 
dormirse con el arrullo musical de: "Doce frailes velan su sueño,/ y una nana cantarán./ San Francisco desde el cielo/ Por el niño velará."

Siguiendo el esquema de Jolivet, se destacan tres grupos de secuencias. Las primeras representan la figura del niño actor, la plasticidad de su rostro y lo gestual de su cuerpo, la riqueza del imaginario de su mundo infantil y la frustración del deseo de madre. Las segundas escenifican la "transgresión" que empiezan después de la "enfermedad" de Marcelino a causa de la picadura del escorpión y un plano de transición. Las terceras metaforizan el canje simbólico. Lo original de Marcelino Pan y Vino estriba en el hecho de que el actante y el coadyuvante del huérfano es un Cristo viviente.

\section{De lo fílmico a lo simbólico}

La figura de la madre aparece una sola vez; es una joven madre. Ese crucial encuentro encamina al pequeño héroe hacia la revelación de un enigma vital en cuanto a su propio origen:

Madre: ¿No tienes padres?

Marcelino: Sí, tengo...doce.

Madre: ¿Doce? ¿Y madre?

M.: Madre no tengo ninguna. ¿Y tú eres madre?

Madre: Sí, tengo dos niños. El mayor es como tú... ¡Manuel! ¡Manuel!

De pronto interrumpe la voz de Fray Papilla que llama a Marcelino y ella a su vez a su hijo Manuel; pero antes de irse corriendo, Marcelino le echa un piropo: “Eres muy guapa!”

Cuando Marcelino llega al convento se dirige primero a la celda de fray Malo y confiesa feliz: "Hoy he visto una madre"; luego se dirige a la cocina donde está fray Papilla y, en medio de una conversación anodina, Marcelino de pronto le pregunta:

M.: ¿Y todos hemos tenido una madre?

Fray Papilla: Claro... todos, tú, yo...

M.: ¿También el padre Superior?

Fray Papilla: También el padre Superior. Todos Marcelino, todos...

M.: ¿Y dónde está la mía?

Fray Papilla: Ya está en el cielo.

M.: ¿Y era guapa?

Fray Papilla: Seguro, era muy guapa.

La sonrisa de felicidad inunda el rostro de Marcelino. En la "novela familiar" que Marcelino se construye se plantea la situación triangular clásica: Fray Papilla desempeńa el papel ambiguo de sustituto materno, aunque también en sentido propio es el padre que asegura la subsistencia y la complicidad viril entre padre e hijo ante la belleza de una mujer. Fray Malo se sitúa del lado 
paterno al aludir a una persona mayor, sabia y de respeto. Situadas a continuación de la aparición de una madre de verdad, estas secuencias escenifican la representación de un punto de giro en la "novela familiar" de Marcelino.

\section{Vitalidad y transgresiones de Marcelino. La interdicción}

Después del encuentro con la aguadora, Marcelino crece en un ambiente de vitalidad y picardía. Cada escena en la que el niño burlón hace travesuras traduce sutilmente la transgresión respecto de la religión y la sexualidad oficiales. La peor broma de Marcelino es nada menos que la violación del ámbito sagrado al interrumpir la oración comunitaria con la irrupción de ruidosas y desordenas cabras y cabritos.

La voz de fray Papilla introduce la prohibición al amonestar al niño:

Has sido muy malo. Todos los frailes están enfadados. Yo también. Y lo estaré aun más si no me obedeces en una cosa. Por la escalera no debes subir nunca. ¿Has oído? Nunca. [...] Allá arriba hay un hombre altísimo que si te ve te cogerá y te llevará para siempre.

La prohibición está representada por la escalera que sube al desván que simboliza, como afirma Jolivet, el "árbol del bien y del mal."

El primer intento de transgresión del objeto de la tentación se lleva a cabo en tres secuencias acompañadas por música religiosa y por las palabras que Marcelino le dirige a Manuel su amigo invisible. ${ }^{8} \mathrm{El}$ silbido de fray Malo viene a interrumpir la primera ascensión. Más adelante las secuencias giran en torno a la picadura del escorpión que provoca el delirio de Marcelino a causa de la fiebre, y representado visualmente con imágenes mentales de la advertencia de fray Papilla sobre el hombre del desván. Marcelino en medio de su delirio se atreve a preguntarle al Padre Superior que está a su lado:

M.: ¿Todas las madres están en el cielo?

PS: Claro... bueno, todas las madres van al cielo.

M.: Entonces, ¿es verdad lo que me ha dicho fray Papilla?

PS: ¿Qué te ha dicho?

M.: Que usted también tiene madre.

PS: Sí....pero la mía ya está en el cielo.

M.: ¿Cómo se va al cielo?”

\footnotetext{
${ }^{8}$ Marcelino poniéndose en el lugar de la madre que le gustaría tener, elige el doble invisible de su deseo fantaseado de ser hijo de aquella madre. Manuel es para Marcelino una especie de amigo "transicional" para suplir la ausencia de su verdadera madre. La diégesis del personaje invisible representa una sutil anticipación del Otro Hijo que no se deja ver pero que su presencia en la pantalla es distinta a la de la luz y la palabra que sustituirá a Manuel en las secuencias del desván prohibido (JOLIVET, 2003: 115).
} 
El diálogo continúa entre ambos recalcando el tema del paraíso-recompensa para los niños buenos.

M.: ¿Y yo soy bueno?

PS: Claro que sí, tú eres muy bueno.

M.: Entonces, ¿puedo ir ya?

PS: Eso depende, Marcelino, de la voluntad de Dios.

Un nuevo intento hacia el desván fantasmagórico

La segunda ascensión al desván consta de dos cuartos; el segundo cuarto es donde yace la imagen de Cristo crucificado. Este segundo ascenso es representado como la profanación de un lugar secreto y prohibido por parte de Marcelino por la presencia visual de una rejilla de confesionario, de hoces, horcas o demás herramientas puntiagudas que connotan la idea de peligro para su cuerpecito infantil (en el imaginario antropológico, representación arcaica del cuerpo femenino, la vagina dentada). De pronto la cámara subjetiva revela en forma ascendente una forma humana erguida en la sombra, en cierto estilo expresionista alemán que dramatiza el asombro y el espanto del niño. Marcelino huye en carrera desenfrenada hacia fuera de la casa convento. Recobrando su naturalidad y hablando con su amigo invisible le dice: “¿Has visto? Era verdad lo que decían los frailes.”

En el segundo intento de subida al desván una vez que Marcelino ha descubierto una figura humana (¿ "el hombre malo" de la prohibición de Fray Papilla?) entra al segundo desván; la cámara descubre entre las tinieblas la silueta fascinante. La percepción de los ojos de Marcelino recorriendo maravillado el cuerpo crucificado recalca, como contiende Jolivet, la distancia ontológica entre lo viviente y lo no-viviente, frente a lo cual Marcelino, ya sin miedo, conmovido por un sentimiento de empatía le dice: "Tienes cara de hambre [...]. Espera, ahora vengo" y Marcelino va a buscar pan.

En el segundo encuentro con Cristo Marcelino no sólo le lleva pan sino vino también. La figura encarnada en ser humano le pregunta:

Jesús: ¿¿No te doy miedo?

M.: No.

Jesús: ¿¿Sabes entonces quién soy?

M.: Sí, eres Dios.

A partir de ese momento Cristo le dice que su apellido será Pan y Vino. Marcelino feliz les comunica a los frailes como signo de afirmación: "yo me llamo Marcelino Pan y Vino."

La escena de la última cena confirma la ficción del niño mesiánico. Fray Papilla descubre las manchas de vino y las sigue hasta la escalera y el padre 
Superior da la orden de seguirlo para revelar el secreto de Marcelino. Luego viene la extraña tormenta que hace correr a Marcelino al desván para proteger a Cristo:

M.: He venido por si tenías miedo.

Cristo: Y tú, Marcelino, ¿̇tienes miedo?

M.: Yo, sí.

Cristo: Acércate a mí.

Cristo: $Y$ ahora vendrá el trueno.

M.: Ahora, ya no importa.

Esta escena marca otro cambio ya que Marcelino tiene un nuevo protector en Cristo y no en el mundo de abajo, el del convento, desatando otra ola de sospechas en fray Papilla, quien lo amonesta al descubrir que Marcelino ha tomado una manta de más.

En la tercera ascensión al desván, la cámara muestra a Marcelino sentado en el suelo dando vueltas distraídamente con el dedo una ruedecita, mientras la voz de Jesús le dice:

La voz de Cristo: Estás muy callado, ¿qué piensas, Marcelino?

M.: ¿¿ónde estará tu madre ahora?

Voz: Con la tuya.

M.: ¿`Y cómo son, qué hacen las madres?

Cristo: Dar, Marcelino, siempre dar.

M.: ¿Qué dan?

Cristo: Dan todo. Se dan a sí mismas. Dan a los hijos sus vidas y la luz de sus ojos hasta quedarse viejas y arrugadas.

M.: ¿Y feas?

Cristo: No, feas, no, Marcelino. Las madres nunca son feas.

A Marcelino su relación confiada con la figura paterna del desván le ha permitido hablar sin miedo de la madre en términos de alteridad.

Mientras suena la campanilla de fray Papilla, Marcelino antes de irse arremete con otra pregunta:

M.: ¿`Y tú quieres mucho a tu madre?

Cristo: Con todo mi corazón.

M.: ¡Y yo a la mía más!

Ha llegado entonces la hora del "juicio" y de la recompensa:

Voz de Cristo: Bien, Marcelino. Has sido un buen muchacho y yo estoy deseando darte como premio lo que tú más quieras. Dime, ¿quieres ser fraile como fray Papilla y el padre Superior? ¿Quieres mejor que venga contigo Manuel?

M.: Sólo quiero ver a mi madre y también a la tuya después.

Voz: ¿`Y quieres verla ahora?

M.: Sí, sí, ahora.

Voz: Tendrás que dormir. 
M.: Pero no tengo sueño.

Voz: Ven, yo te lo daré.

M.: Bueno...

Voz: Duerme, pues, Marcelino.

El travelling de la cámara y la reaparición del sillón desde donde habla el que no se puede ver, muestra un brazo con ademán acogedor, sinécdoque de la figura divina encarnada. Fray Papilla, que descubre el "milagro", llama al resto de los frailes. Luego en un primerísimo plano se deja ver el regreso de Cristo a la cruz; un truco con el hombre-estatua reapareciendo en sobreimpresión sobre la cruz, restableciendo el "milagro oficial de la muerte."

\section{Epílogo}

El final del flashback regresa al presente de la estructura abismada y a los comentarios de la voz en off. El joven fraile, ya fuera de la casa de la nińa enferma (que suponemos ha muerto), se dirige al convento en lo alto de una colina mientras las gentes del pueblo (el mundo de abajo), están arriba celebrando el milagro de Marcelino en el convento. ¿Cómo interpretar la muerte milagrosa del nińo en el convento? Como sostiene Jolivet, la dormición/crucifixión seguida de la reconciliación social ha llevado a cabo el proceso de "sacralización" de la muerte del niño, una variante del motivo del niño mesiánico como chivo expiatorio sacrificado para reconciliar un grupo social dividido, el de arriba católico, el de abajo laico, republicano.

El montaje del filme vendría a ser una variante reactualizada de los mitos arcaicos del niño sin origen, cuya muerte como víctima propiciatoria alimenta el mito del Otro absoluto y esa religión pervertida de la ley del Padre sobre la que se fundan todos los sistemas totalitarios. Su montaje simbólico podría encubrir el reflejo de las grandes maniobras dogmáticas del poder (cuestión del Padre) y de lo prohibido (el deseo). La película viene a representar tanto el equivalente del discurso de legitimación del poder en que la España nacional-católica como su deseo de sublimación de la muerte del inocente en el altar de la Madre (Iglesia/Patria). No es una coincidencia que en España en esa época se produzcan una variedad de actos simbólicos que apuntan a la redención de una situación de guerra fratricida. Marcelino Pan y Vino es una de esas manifestaciones simbólicas, junto con el Valle de los Caídos, que comenzado en 1940 e inaugurado en 1959, homenajea oficialmente la memoria de "todos" los caídos en la trágica novela familiar-nacional como otro acto simbólico a través del signo de un gran crucifijo. En la guerra fratricida se impone la necesidad de la reconciliación. Santos Juliá (1999) señala que si en el mito de las dos España pueden hallarse muchas 
de las razones de una guerra de exterminio contra un invasor interno, en el mito de la reconciliación nacional, otros fundaron la razón de la guerra fratricida; en este caso en el decir de Ernest Renan debe olvidarse ese pasado para poder reconstruir otra nación y otro Estado. Un largo recorrido hubo que atravesar en los veinte ańos que siguieron al conflicto fratricida, entre 1936 y 1956, período que abarca nuestro film, para que la posibilidad de un nuevo relato (aún no cumplido), emergiera y que culminara con el encuentro en Munich de 1962, donde se ratificó la necesidad de amnistía, "aun si a los comunistas sólo se les permitió entonces una presencia en los pasillos" (47). Relato que, sin embargo, los que se mantuvieron dentro del régimen no sufrieron y que aún sigue como una agenda oficial no totalmente saldada. Los filmes que mencionáramos al principio de este trabajo contribuyen de un modo simbólico a reparar ese saldo que no ha sido satisfecho en la imaginación nacional y la Ley de Memoria Histórica que el gobierno de José Luis Rodríguez Zapatero sancionara en los albores del nuevo milenio (2007) es un intento constitucional de satisfacer esa asignatura pendiente de aquel contrato, entre otros, de 1962.

\section{Bibliografía}

CAMPORESI, Valeria. "Para una historia de lo no nacional en el cine español. Ladislao Vajda y el caso de los huidos de las persecuciones antisemitas en Espańa”, en Nancy Berthier y Jean-Claude Seguin, comps. Cine, nación y nacionalidad en España. Madrid: Casa de Velázquez, 2007: 61-74.

GUBERN, Román. "Teoría y práctica del Star-System infantil”, Archivos de la Filmoteca n. 38, Valencia: Ediciones de la Filmoteca, 2001: 5-84.

HARVEY, Jessamy. "Death and the adorable orphan: Marcelino pan y vino (1954; 1991; 2000)", Journal of Romance Studies, volumen 4.1, 2004: 63-77.

JOLIVET, Anne-Marie. La pantalla subliminal. Marcelino pan y vino según Vajda. Valencia: Ediciones de la Filmoteca, 2003.

JULIÁ, Santos. "De 'guerra contra el invasor' a 'guerra fratricida”. In: (Coord.) Victimas de la guerra civil. Madrid: Temas de Hoy, 1999: 11-52.

Marcelino pan y vino. Dir. Vajda, Ladislao. Guión Ladislao Vajda y José María Sánchez Silva, 1954. Film.

RUBIO, Pablo. Crímenes contra el Estado: El género policial fílmico en la España de la segunda década de la autarquía (1950-1959) y en la Argentina del Primer Peronismo (1946-1956). Tesis doctoral, 2014.

SÁNCHEZ SILVA, José María. Marcelino Pan y Vino. Editorial Andrés Bello. Santiago de Chile, 1989 [1952].

Rita De Grandis. Professora Titular de Literatura Hispanoamericana (Dedicação exclusiva em The University of British Columbia, Vancouver, Canadá. Doutora em 
Literatura comparada pela Université de Montréal. Autora de Reciclaje cultural y memoria revolucionaria: La práctica polémica de José Pablo Feinmann (Argentina: Biblos, 2006), e de Polémica y estrategias narrativas en América Latina (Argentina: Beatriz Viterbo Editora, 1993). Publicou artigos críticos en revistas arbitradas (Revista Canadiense de Estudios Hispánicos, Latin American Popular Culture, Latin American Literary Review, Revista de Crítica Literaria Latinoamericana) e em livros em colaboração. 